\title{
The extraction and application of fault characteristic vector for lower vacuum of condenser in 1000MW unit
}

\author{
CHEN Wen ${ }^{1}$, YAN Tao ${ }^{1, a}$, CAI Wen ${ }^{1}, Y_{\text {ang Hong-yan }}^{2}$, WAN Zhong-hai ${ }^{1}$ \\ ${ }^{1}$ State Grid JiangXi Electric Power Research Institute, Nanchang 330096,Jiangxi Province,China \\ ${ }^{2}$ Shanghai Pengken Energy Technology Co.LTD, Shanghai 200090,China
}

\begin{abstract}
In this paper the failure sets and symptom sets of the problem for a $1000 \mathrm{MW}$ unit were determined. On the basis of distinguishing the precipitous decline and slow decline of vacuum, the calculation model of the state quantization value of every symptom parameter was established and the fault characteristic vector of the lower vacuum of the condenser was obtained by the simulation test of the unit. Based on BP neural network, the fault diagnosis model of condenser was established, and the low vacuum fault of the unit was diagnosed. The results show that the fault diagnosis of condensers can be used in the actual unit operation according to the fault theory domain feature vector of $1000 \mathrm{MW}$ unit.
\end{abstract}

\section{Introduction}

The fault diagnosis of condenser system is a branch of fault diagnosis of thermal power unit, and low vacuum of condenser is the most frequent and complicated fault ${ }^{[1]}$.Early power station operators are based on operational experience to determine the cause of condenser failure. From 1990s ${ }^{[2]}$, some scholars began to research low vacuum of condenser through intelligent technologies such as fuzzy mathematics ${ }^{[3]}{ }^{[4]}$, the BP neural network, grey correlation method ${ }^{[5]}$, the fault tree model ${ }^{[6]}$, genetic algorithm, integrated diagnosis method ${ }^{[7]}$, etc. The core of these methods is to establish the mapping relationship between the low vacuum fault sets and symptom sets by using different diagnostic methods to determine the cause of the vacuum-induced drop ${ }^{[9]}$. However, the diagnosis is based on the establishment of fault characteristic vectors, which is the relationship between the cause of the malfunction and the signs of change in online monitoring data. Due to the variety of operation modes of the units, the structure, performance of the thermal equipment and thermal system are complicated. The faults have dynamic time-varying characteristics and the degree of faults can be large or small ${ }^{[9]}$. The common method of extracting theory domain eigenvectors such as the field operation experience, the theoretical analysis of the condenser fault [1], there are always some limitations, and fault theory domain feature vectors should be fixed combined with specific equipment and systems for different units. However, the existing literature does not give a detailed method of establishing the fault characteristic vector of the condenser instead of giving the result that the symptom appears (the characteristic value is taken as 1) or not (the characteristic value is taken as 0 ). Therefore it is necessary to study the establishment of the theory domain feature vector of low vacuum fault in condenser.

In this paper, a $1000 \mathrm{MW}$ unit is taken as an example. Through several experiments on simulation, the threshold value of the symptom parameter is obtained, and the fault diagnosis is verified on the actual unit.

\section{Fault symptom set of condenser}

Due to the difference of structure, equipment and systems for units, the condenser fault symptom set is not the same. The unit studied in this paper is an ultrasupercritical intermediate reheat condensing steam turbine $\left(\mathrm{N} 1000-26.25 \mathrm{MPa} / 600^{\circ} \mathrm{C} / 600^{\circ} \mathrm{C}\right)$, which is fourcylinder and four-row steam construction with 8 stage steam extraction. The condenser is double back pressure N-54000 type, double shell, single flow, surface type, horizontal arrangement, which equips with two EVMA250 type vacuum pumps. The cooling water system is equipped with two $2600 \mathrm{VZNM}$ circulating water pumps. The condenser low vacuum fault symptom sets are shown in Table 1.

Table 1. Symptom set of condenser

\begin{tabular}{ll|ll}
\hline Items & symptom parameter & Items & symptom parameter \\
\hline B1 & Vacuum of condenser A & B16 & Electricity of vacuum pump A \\
B2 & Vacuum of condenser B & B17 & Electricity of vacuum pump B \\
B3 & Electricity circulating pump A & B18 & Outlet pressure of condensate pump A
\end{tabular}

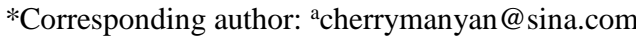




\begin{tabular}{|c|c|}
\hline B4 & Electricity circulating pump B \\
\hline B5 & Water resistance of condenser \\
\hline B6 & $\begin{array}{l}\text { Differential expansion of low } \\
\text { pressure cylinder rotor }\end{array}$ \\
\hline B7 & $\begin{array}{l}\text { Motor electricity of condensate } \\
\text { pump A }\end{array}$ \\
\hline B8 & $\begin{array}{l}\text { Motor electricity of condensate } \\
\text { pump B }\end{array}$ \\
\hline B9 & $\begin{array}{l}\text { Water level of low-pressure } \\
\text { heater 7\# }\end{array}$ \\
\hline B10 & $\begin{array}{l}\text { Water level of low-pressure } \\
\text { heater } 8 \#\end{array}$ \\
\hline B11 & $\begin{array}{l}\text { Temperature rise of circulating } \\
\text { water }\end{array}$ \\
\hline B12 & $\begin{array}{l}\text { Heat transfer difference of } \\
\text { condenser }\end{array}$ \\
\hline B13 & Condensate depression of water \\
\hline B14 & $\begin{array}{l}\text { Water level of condenser hot } \\
\text { well A }\end{array}$ \\
\hline B15 & $\begin{array}{l}\text { Water level of condenser hot } \\
\text { well B }\end{array}$ \\
\hline
\end{tabular}

The online monitoring parameters are divided into normal, increased, and decreased cases. The quantified values of the characteristic parameters that defined the symptoms are $0.0,0.5$, and 1.0, respectively. In other words, the state quantification value of the symptom parameter Bj can be determined by Formula (1).

$B_{j}=\left\{\begin{array}{cc}0.0 & \text { normal } \\ 0.5 & \text { increased } \\ 1.0 & \text { decreased }\end{array}\right.$

\section{Characterization of the symptom parameter}

Generally there are two kinds of characteristic methods for symptom parameters ${ }^{[10]}$ : The first one judge the positive and negative rate values of change about the parameters per unit time. The advantage of this method is that it is very sensitive to the faults in the initial stage of the fault, but it is lack of a stable maintenance. The second one is based on the deviation and threshold of the parameter operating value and the expected value. The advantage is that the symptom can be maintained for a
Outlet pressure of condensate pump B

Outlet pressure of circulating pump A

Outlet pressure of circulating pump B

Filter screen pressure of pre-condensate pump A

Filter screen pressure of pre-condensate pump B

Inlet water temperature of low-pressure heater $8 \#$

Outlet water temperature of low-pressure heater

$8 \#$

Outlet water temperature of low-pressure heater

$7 \#$

Outlet water temperature of steam-water

separator A

Outlet water temperature of steam-water

separator B

Electricity of steam-water separator A bypass

pump

Electricity of steam-water separator B bypass

long time, but the determination of the deviation and the threshold are more complicated.

For the fault that causes the vacuum to decline sharply and the unit to trip, it is necessary to discover and take corresponding remedial measures in time. Therefore, the corresponding symptoms should be characterized by the positive and negative rate values of change about the parameters when a fault occurs in the unit. For the fault that causes the vacuum to decline slowly, it can be characterized according to the deviation and the threshold of the parameter operating value and expected value when corresponding symptom parameters change slowly.

\subsection{Fault identification causing precipitous and slow decline in vacuum}

For example, various failures of low vacuum occurred in the unit simulator when the unit operates under condition of 700MW. The degree of vacuum of condenser A and condenser B is monitored, and the magnitude of change rate for the average value to time is used as a criterion for judging whether or not malfunction causing precipitous decline in vacuum. The test results are shown in Table 2.

Table 2 The fault symptom set of condenser

\begin{tabular}{|c|c|c|c|c|c|}
\hline Items & Fault parameter & $\begin{array}{l}\text { rate of change } \\
\text { (a) }\end{array}$ & $\begin{array}{c}\text { Item } \\
\mathrm{s} \\
\end{array}$ & Fault parameter & $\begin{array}{l}\text { rate of change } \\
\text { (a) }\end{array}$ \\
\hline A1 & Leakage of water pipe at low pressure heater $7 \#$ & 0.0070 & A6 & $\begin{array}{l}\text { Circulating pump B } \\
\text { tripping and jury pump } \\
\text { disconnecting }\end{array}$ & 0.0028 \\
\hline $\mathrm{A} 2$ & Leakage of water pipe at low pressure heater $8 \#$ & 0.0135 & A7 & Leakage of vacuum system & 0.4668 \\
\hline A3 & Circulating pump A tripping & 0.0263 & A8 & $\begin{array}{l}\text { The vacuum breaker } \\
\text { opening }\end{array}$ & 1.1794 \\
\hline A4 & Circulating pump B tripping & 0.0263 & A9 & $\begin{array}{l}\text { Circulating Water } \\
\text { interrupting }\end{array}$ & 1.6411 \\
\hline A5 & $\begin{array}{l}\text { Circulating pump A tripping and jury pump } \\
\text { disconnecting }\end{array}$ & 0.0028 & & & \\
\hline
\end{tabular}

The change rate of the faults A8 and A9 is much greater than the other faults under conditions of $700 \mathrm{MW}$, and the experimental results are the same under other conditions according to Table 2. Therefore, it can be confirmed that the faults A8 and A9 cause a precipitous decline in vacuum, while the remaining faults are faults causing a slow decline in the vacuum. In actual operation, the average value about the minimum value of the change rate with precipitous decline and the maximum value of the change rate with slow decline is the defined value(about 0.8 ):

$\left\{\begin{array}{lll}a \geq 0.8 & \text { rapid } & \text { drop } \\ a<0.8 & \text { slow } & \text { drop }\end{array}\right.$ 


\subsection{Method of determining deviation about symptom parameter}

For the fault with slow decline, the expression of symptom parameters is based on deviation and threshold. Noting the parameter running value, the expected value and the deviation value is $\mathrm{X}, \mathrm{X} 0$ and $\mathrm{Y}$, respectively. Deviation $\mathrm{Y}$ has two kinds of calculation methods:

$$
\begin{aligned}
& \text { Method One: } Y_{1}=X-X_{0} \\
& \text { Method Two: } Y_{2}=\left(X-X_{0}\right) /\left|X_{0}\right|
\end{aligned}
$$

The first method is the absolute amount of deviation, which result in missed sentence easily because of large deviation calculated. On the other hand, method 2 calculates the relative deviation concentrated on $[-1,1]$, which can avoid the occurrence of missed judgement and is more conducive to comparative judgment. Therefore, the second method is chosen to calculate the deviation of the operating value and the expected value of the symptom parameter.

\section{Fault characteristic vector}

\subsection{Fault characteristic vector causing slow decline in vacuum}

Table 3 The quantification value of symptom state parameter

in $\mathrm{A} 1-\mathrm{A} 7$

\begin{tabular}{c|ccc}
\hline $\begin{array}{c}\text { symptom } \\
\text { parameter }\end{array}$ & $\begin{array}{c}\text { Range of } \\
\text { deviation }\end{array}$ & $\begin{array}{c}\text { State of symptom } \\
\text { parameter }\end{array}$ & $\begin{array}{c}\text { Quantification } \\
\text { value }\end{array}$ \\
\hline \multirow{2}{*}{ B1、B2 } & $\mathrm{Y} \leq 0.0002$ & increase & 0.5 \\
& $\mathrm{Y}>0.0002$ & decrease & 1.0 \\
& $\mathrm{Y}<-0.1$ & normal & 0.0 \\
B9、B10 & $-0.1 \leq \mathrm{Y} \leq 0.1$ & increase & 0.5 \\
& $\mathrm{Y}>0.1$ & decrease & 1.0 \\
& $\mathrm{Y}<-0.001$ & normal & 0.0 \\
& - & & \\
other & $0.001 \leq \mathrm{Y} \leq 0$ & increase & 0.5 \\
& .001 & & \\
& $\mathrm{Y}>0.001$ & decrease & 1.0 \\
\hline
\end{tabular}

For faults causing a slow vacuum decline, the symptom parameters are characterized according to the deviations of the parameter operating values from the expected values and the threshold values calculated by formula (3).
Under the normal operating conditions of the unit $700 \mathrm{MW}$, the symptom parameter deviation value of A1A7 can be calculated. And then, it can be determined the thresholds for each symptom state corresponding to the faults A1-A7, and define the scope of the symptom parameter deviation from the deviation values of the symptom parameters. The quantification value of the symptom parameters according to equation (1) is shown in Table 3.

The quantification value of each symptom parameter is established by performing a failure test under $700 \mathrm{MW}$ operating conditions in table 4 . The same fault tests were performed for other conditions. The quantification value of the symptom reference state obtained according to formula (1) was completely consistent with Table 3 although different deviation under other conditions.

\subsection{Fault characteristic vector causing precipitous decline in vacuum}

Faults A8 and A9 would cause a precipitous decline in vacuum, and they will be tested separately under 700 MW conditions. The change rate of each symptom parameter relative to time can be calculated. And then, it can be determined the state threshold of each symptom parameter corresponding to the occurrence of faults $\mathrm{A} 8$ and A9, and define the scope of the symptom parameter deviation from the change rate. The parameter quantification values A8 and A9 obtained by formula (1) are shown in Table 4.

Table 4 The Quantification value of symptom state parameter in $\mathrm{A} 8$ and $\mathrm{A} 9$

\begin{tabular}{c|cc}
\hline range & $\begin{array}{c}\text { State of symptom } \\
\text { parameter }\end{array}$ & $\begin{array}{c}\text { Quantification } \\
\text { value }\end{array}$ \\
\hline $\mathrm{a} \leq-0.5$ & normal & 0.0 \\
$0.5 \leq \mathrm{a}$ & increase & 1.0 \\
$-0.5<\mathrm{a}<0.5$ & decrease & 0.5 \\
\hline
\end{tabular}

The quantification value of each symptom parameter is established by performing a failure test under $700 \mathrm{MW}$ operating conditions in table 4 . The same fault tests were performed for other conditions.

The condenser low vacuum fault feature vector set applied to any conditions of the unit can be established according to Table 3 and Table 4, as shown in Table 5.

Table 5 The fault theory domain feature vector set of 1000MW condensing unit

\begin{tabular}{llllllllll|llllllllllllll}
\hline symptom & A1 & A2 & A3 & A4 & A5 & A6 & A7 & A8 & A9 & symptom & A1 & A2 & A3 & A4 & A5 & A6 & A7 & A8 & A9 \\
\hline B1 & 1.0 & 1.0 & 1.0 & 1.0 & 1.0 & 1.0 & 1.0 & 1.0 & 1.0 & B16 & 0.5 & 0.5 & 0.5 & 0.5 & 0.0 & 0.5 & 0.5 & 0.5 & 0.5 \\
B2 & 1.0 & 1.0 & 1.0 & 1.0 & 1.0 & 1.0 & 1.0 & 1.0 & 1.0 & B17 & 0.5 & 0.5 & 0.5 & 0.5 & 0.5 & 0.0 & 0.5 & 0.5 & 0.5 \\
B3 & 0.5 & 0.5 & 0.0 & 1.0 & 0.5 & 0.5 & 0.5 & 0.5 & 0.0 & B18 & 1.0 & 0.0 & 0.5 & 0.5 & 0.5 & 0.5 & 0.0 & 0.5 & 0.5 \\
B4 & 0.5 & 0.5 & 1.0 & 0.0 & 0.5 & 0.5 & 0.5 & 0.5 & 0.0 & B19 & 1.0 & 0.0 & 0.5 & 0.5 & 0.5 & 0.5 & 0.0 & 0.5 & 0.5 \\
B5 & 0.5 & 0.5 & 0.0 & 0.0 & 0.5 & 0.5 & 0.5 & 0.5 & 0.0 & B20 & 0.5 & 0.5 & 0.0 & 0.0 & 0.5 & 0.5 & 0.5 & 0.5 & 0.0 \\
B6 & 0.0 & 0.5 & 0.5 & 0.5 & 0.5 & 0.5 & 0.0 & 0.5 & 0.5 & B21 & 0.5 & 0.5 & 0.0 & 0.0 & 0.5 & 0.5 & 0.5 & 0.5 & 0.0 \\
B7 & 0.0 & 1.0 & 0.5 & 0.5 & 0.5 & 0.5 & 1.0 & 0.5 & 0.5 & B22 & 0.0 & 1.0 & 0.5 & 0.5 & 0.5 & 0.5 & 1.0 & 0.5 & 0.5 \\
B8 & 0.0 & 1.0 & 0.5 & 0.5 & 0.5 & 0.5 & 1.0 & 0.5 & 0.5 & B23 & 0.0 & 1.0 & 0.5 & 0.5 & 0.5 & 0.5 & 1.0 & 0.5 & 0.5 \\
B9 & 0.0 & 1.0 & 0.5 & 0.5 & 0.5 & 0.5 & 0.5 & 1.0 & 1.0 & B24 & 0.0 & 1.0 & 0.5 & 0.5 & 0.5 & 0.5 & 1.0 & 0.5 & 0.5 \\
B10 & 0.0 & 1.0 & 0.5 & 0.5 & 0.5 & 0.5 & 0.5 & 1.0 & 1.0 & B25 & 1.0 & 0.0 & 0.5 & 0.5 & 0.5 & 0.5 & 1.0 & 0.5 & 0.5
\end{tabular}




\begin{tabular}{|c|c|c|c|c|c|c|c|c|c|c|c|c|c|c|c|c|c|c|c|}
\hline B11 & 0.0 & 1.0 & 1.0 & 1.0 & 0.5 & 0.5 & 1.0 & 0.5 & 0.5 & B26 & 1.0 & 1.0 & 0.5 & 0.5 & 0.5 & 0.5 & 1.0 & 0.5 & 0.5 \\
\hline B12 & 1.0 & 0.0 & 0.0 & 0.0 & 1.0 & 1.0 & 1.0 & 1.0 & 1.0 & B27 & 0.5 & 0.5 & 1.0 & 1.0 & 1.0 & 0.5 & 0.5 & 0.5 & 0.5 \\
\hline B13 & 1.0 & 1.0 & 1.0 & 1.0 & 0.0 & 0.0 & 1.0 & 1.0 & 1.0 & B28 & 0.5 & 0.5 & 1.0 & 1.0 & 0.5 & 1.0 & 0.5 & 0.5 & 0.5 \\
\hline B14 & 0.5 & 0.5 & 1.0 & 1.0 & 0.5 & 0.5 & 1.0 & 0.5 & 0.5 & B29 & 0.5 & 0.5 & 0.5 & 0.5 & 0.0 & 0.5 & 0.5 & 0.5 & 0.5 \\
\hline B15 & 0.5 & 0.5 & 1.0 & 1.0 & 0.5 & 0.5 & 1.0 & 0.5 & 0.5 & B30 & 0.5 & 0.5 & 0.5 & 0.5 & 0.5 & 0.0 & 0.5 & 0.5 & 0.5 \\
\hline
\end{tabular}

\section{Test of fault diagnosis for low vacuum of condenser}

A BP neural network was used to establish a condenser fault diagnosis model based on the fault symptom vector set of the condenser of a $1000 \mathrm{MW}$ unit in Table 7.

The BP neural network input layer corresponds to the state quantification value of the symptom parameters, the number of nodes is 30 ; the output layer corresponds to a low vacuum fault level, and the number is 9 . The ideal range of neurons in the hidden layer is [20, 49]. The neural network topology with the smallest mean-square error is selected: $30-40-9$ by comparison.

The circulating pump A is tripped under 550MW condition. The symptom set feature vector corresponding to the new condition is obtained by formula (1) 、 formula (3)、 table 4 and table 5 according to the monitoring parameters:

$[B]=[1.0,1.0,0.0,1.0,0.0,0.5,0.5,0.5$, $0.5,0.5,1.0,0.0,1.0,1.0,1.0,0.5,0.5,0.5$, $0.5,0.0,0.0,0.5,0.5,0.5,0.5,0.5,1.0,1.0$, $0.5,0.5]$

Inputting to the trained BP neural network, the output vector of the network is:

$[\mathrm{A}]=[0.0003,0.0061,0.9805,0.0157,0.0025$, $0.0090,0.0048,0.0001,0.0076]$

The maximum output value of the network is 0.9805 corresponding to A3. Compared with the fault set of low vacuum in table 2, it can be known that the fault occurred is the trip of the circulating pump A. The diagnosis result is consistent with the fault setting, which indicates that the fault theory domain characteristic vector of the $1000 \mathrm{MW}$ unit according to the simulator test can be used for the fault diagnosis of the condenser in the actual unit operation.

\section{Conclusions}

(1)In view of the difference of descent speed in the vacuum when the condenser low vacuum occurs, two different symptom parameter calculation methods are selected to establish the calculation model, and the vacuum degree relative to time is determined by the simulation test of the unit simulator. It is discriminated a malfunction causing precipitous decline in the vacuum whether or not the rate exceeds 0.8 .

(2)For the fault causing a slow vacuum decline, the symptom parameter is calculated by the state threshold from the relative deviation between the parameter operating value and the expected value, then the state quantification value of the symptom parameter is obtained; for the fault causing a precipitous vacuum decline, the calculation method is obtained by comparing the magnitude of the change rate of the parameter with respect to time. According to this method, the state quantification value of the symptom parameter can be calculated.

(3)The symptom vector set of the low vacuum fault for the condenser of the $1000 \mathrm{MW}$ unit was obtained according to the tests and calculations of (1) and (2). The result of condenser fault diagnosis model established by BP neural network is accurate. It shows that the fault symptom vector set for the condenser of the $1000 \mathrm{MW}$ unit in this paper can be used to diagnose the condenser low vacuum problem during the actual unit operation.

\section{References}

1. Wang Bo. Master Thesis, The Quantitative Diagnosis and Research on Condenser Vacuum Reduction in Power Plant Based on FAHP. Beijing: north China electric power university,(2012)

2. Li Yong, Ye Rongxue, Cao Zuqing. TURBINE TECHNOLOGY, The fault membership function and fuzzy diagnosis method based on BP network. Vol.37 No.4: 199-203 (1995)

3. Lu Xuxiang, Li Wenping. TURBINE TECHNOLOGY, Estimation for Operating State of Condensers Based on Fuzzy Synthesis Judgment. Vol.43 No.5: 301-303 (2001)

4. Teng Pi-Zhong, Zhang Pin,Chen Rong-Sheng. Dianli Zidonghua Shebei /Electric Pover Automation Rquipment, Fault diagnosis and performance supervision of condenser based on fuzzy neural network. Vol.27, No.1: 90-92, (2007)

5. Chen Xiaoshan, Qiu Ailing, Jia Honggang. Journal Of Northeast Dianli University Natural Science Edition, The Diagnosis Method of Grey Correlation Degree to Reason of Vacuum Reduction of the Condenser. Vol.27 No.6: 33-36 (2007)

6. Pei Jie, Zhou Meng, Zhou Xinjun et al. ELECTRIC POWER, Fault diagnosis system based on fault tree for condenser in low-vacuum operation. Vol.41 No.4: 57-61, (2008)

7. Cao Lihua, Wang Hongyu, Li Yong. TURBINE TECHNOLOGY, Fault Diagnosis Method of Condenser Base on the Fusion of Multi-neural Networks and D-S Evidence Theory. Vol.52 No.2: 122-124 (2016)

8. Wang lei, Zhang Ruiqing, Sheng Wei. Journal of Engineering for Thermal Energy \& Power , Diagnosis of Condensers Faults Based on Fuzzy Rules and a Support Vector Machines. Vol.24 No.4: 476-480 (2009) 
9. Ma Liangyu, Wang Bingshu, Gao Jianqiang. Journal of Engineering for Thermal Energy \& Power, A Study on the Extraction of Sample Knowledge Concerning Faults and Malfunctions of a Dualchannel Steam Condenser on the Basis of a Simulation Model. Vol.16 No.93: 298-302 (2001)

10. Ding Yan. Master Thesis, Research of the Dynamical Mathematical Model and the Fault Diagnosis of Condenser. Wuhan: wuhan university(2005) 